\title{
Investigating unsaturated fat, monensin, or bromoethanesulfonate in continuous cultures retaining ruminal protozoa. I. Fermentation, biohydrogenation, and microbial protein synthesis ${ }^{1}$
}

\author{
S. K. R. Karnati, ${ }^{,} \dagger^{2}$ J. T. Sylvester, ${ }^{*}{ }^{3}$ C. V. D. M. Ribeiro, $\dagger$ L. E. Gilligan, $\dagger$ and J. L. Firkins ${ }^{*} \dagger$ \\ ${ }^{*}$ Ohio State University Interdisciplinary Nutrition Program (OSUN), and \\ †Department of Animal Sciences, The Ohio State University, Columbus 43210
}

\section{ABSTRACT}

Methane is an end product of ruminal fermentation that is energetically wasteful and contributes to global climate change. Bromoethanesulfonate, animal-vegetable fat, and monensin were compared with a control treatment to suppress different functional groups of ruminal prokaryotes in the presence or absence of protozoa to evaluate changes in fermentation, digestibility, and microbial $\mathrm{N}$ outflow. Four dual-flow continuous culture fermenter systems were used in 4 periods in a $4 \times 4$ Latin square design split into 2 subperiods. In subperiod 1, a multistage filter system $(50-\mu \mathrm{m}$ smallest pore size) retained most protozoa. At the start of subperiod 2 , conventional filters $(300-\mu \mathrm{m}$ pore size) were substituted to efflux protozoa via filtrate pumps over 3 $\mathrm{d}$; after a further $7 \mathrm{~d}$ of adaptation, the fermenters were sampled for $3 \mathrm{~d}$. Treatments were retained during both subperiods. Flow of total N and digestibilities of NDF and $\mathrm{OM}$ were 18,16 , and $9 \%$ higher, respectively, for the defaunated subperiod but were not different among treatments. Ammonia concentration was $33 \%$ higher in the faunated fermenters but was not affected by treatment. Defaunation increased the flow of nonammonia $\mathrm{N}$ and bacterial $\mathrm{N}$ from the fermenters. Protozoal counts were not different among treatments, but bromoethanesulfonate increased the generation time from 43.2 to $55.6 \mathrm{~h}$. Methanogenesis was unaffected by defaunation but tended to be increased by unsaturated fat. Defaunation did not affect total volatile fatty acid production but decreased the acetate:propionate ratio; monensin increased production of isovalerate and valerate. Bio-

Received June 9, 2008

Accepted April 28, 2009.

${ }^{1}$ Research was supported by state and federal funds appropriated to the Ohio Agricultural and Development Center, The Ohio State University. Manuscript number 9/08AS. Additional support was provided by the USDA Cooperative State Research, Education, and Extension Service USDA/NRICGP Grant 2003-35206-12872 and Elanco Animal Health (Greenfield, IN).

${ }^{2}$ Corresponding author: karnati.1@osu.edu

${ }^{3}$ Current address: Buckeye Nutrition, Dalton, OH 44618. hydrogenation of unsaturated fatty acids was impaired in the defaunated fermenters because effluent flows of oleic, linoleic, and linolenic acids were 60,77 , and $69 \%$ higher, and the ratio of vaccenic acid:unsaturated FA ratio was decreased by $34 \%$ in the effluent. This ratio was increased in both subperiods with the added fat diet, indicating an accumulation of intermediates of biohydrogenation. However, the flow of 18:2 conjugated linoleic acid was unaffected by defaunation or by treatments other than added fat. The flows of trans-10, trans-11, and total trans-18:1 fatty acids were not affected by monensin or faunation status.

Key words: methane, protozoa, bromoethanesulfonate, monensin

\section{INTRODUCTION}

Research has focused on decreasing methanogenesis to reduce the environmental impact of dairy operations, but also because it should theoretically improve the efficiency of conversion of digestible energy to ME. Many researchers have evaluated methods to inhibit methanogens directly through various additives or indirectly by suppressing the abundance of protozoa and their harbored ecto- or endosymbionts (Hegarty, 1999). Unfortunately, if digestibility is decreased or microbial protein production is shifted to the hindgut, defaunation to reduce protozoal-associated methanogens might decrease methanogenesis per animal but not decrease the amount of methane produced per unit of milk production, negating its effectiveness for methane abatement strategies (Beauchemin et al., 2008; Firkins et al., 2008). Future efforts to reduce methanogenesis should be enhanced by a better understanding of the complexity of the rumen microbial ecosystem.

Optimizing the yield of microbial protein and VFA from ruminal degradative processes depends on microbial competition for nutrients but also synergism among anaerobic bacteria, methanogenic archaea, fungi, and protozoa. Methane production keeps the $\mathrm{H}_{2}$ concentration low, thus shifting fermentation by $\mathrm{H}_{2-}$ 
producing saccharolytic bacteria and protozoa toward higher ATP-yielding pathways (Wolin et al., 1997). The bacteria that replace the niche left after defaunation or protozoal suppression also can produce $\mathrm{H}_{2}$. In fact, cellulolytic bacteria produce variable, but potentially large amounts of, $\mathrm{H}_{2}$ (Wolin et al., 1997), and protozoa might indirectly benefit fibrolytic bacteria (Firkins and Yu, 2006). Consequently, methane inhibitors or defaunation could concomitantly decrease the yield of fibrolytic bacteria and decrease NDF digestibility, thus negating the benefit. To avoid various complications associated with the defaunation process or maintenance of unfaunated cattle (Firkins et al., 2007) plus the measurement of methane (Firkins et al., 2008) and VFA (Firkins et al., 2006) production rates in vivo, our primary objective was to adapt our continuous culture system to maintain and then efflux protozoa to study their interactions with bacteria and archaea while quantitatively measuring fermentation production rates.

Monensin is a common feed additive that is expected to decrease the production of $\mathrm{H}_{2}$, and thereby methane (McGuffey et al., 2001), but much of the foundational work was based on studies with beef cattle fed highgrain diets or using pure cultures of bacteria. However, even some gram-positive strains adapt to it in vitro (Russell and Houlihan, 2003) and apparently in vivo (Weimer et al., 2008). Less is known about inhibition of monensin toward ciliate protozoa (Weimer et al., 2008), but our work documented a profound initial inhibition followed by gradual adaptation in vitro (Sylvester et al., 2009) and found no effect in lactating dairy cattle after an adaptation period (Oelker et al., 2009). In addition, monensin has been suggested to decrease the extent of biohydrogenation (BH) because it inhibits lipolytic bacteria (McGuffey et al., 2001). Using real-time PCR, Weimer et al. (2008) noted a decrease in Butyrivibrio fibrisolvens, but not Eubacterium ruminantium, associated with feeding monensin to dairy cattle. The butyrivibrios, including these latter 2 species, are spread across 3 clusters of various genera of gram-positive bacteria (Maia et al., 2007; Paillard et al., 2007). In addition to degrading hemicellulose and various other carbohydrates, members of this group are predominant in lipolysis, vaccenic acid (VA; trans-11 18:1) production, and VA reduction to stearic acid. Butyrivibrios produce variable amounts of $\mathrm{H}_{2}$ (Cotta and Forster, 2006); consequently, VFA fermentation patterns and methane production might directly influence, or be indicative of, shifts in major groups of biohydrogenating bacteria.

Dietary unsaturated fats are common in dairy nutrition and can have a variety of effects on microbial metabolism in the rumen, including potentially decreasing methanogenesis (Beauchemin et al., 2008). Protozoa can be inhibited by fat (Firkins et al., 2007) but can also potentially affect $\mathrm{BH}$ either by increasing the rate of lipolysis of dietary triglycerides or by incorporating unsaturated fatty acids (FA) or $\mathrm{BH}$ intermediates such as VA into their cell membranes (Devillard et al., 2006). A protozoal predation preference has been noted toward B. fibrisolvens (Williams and Coleman, 1992). Because a greater inhibition by unsaturated FA is correlated with the enzymatic capability for specific butyrivibrios to complete BH to fully saturated FA (Maia et al., 2007), the interactions of various butyrivibrios with protozoa might profoundly affect the accumulation of $\mathrm{BH}$ intermediates when unsaturated fat is fed (Boeckaert et al., 2007).

Unsaturated fat was expected to be directly toxic to ciliate protozoa, methanogens, and gram-positive bacteria while being less inhibitory to gram-negative bacteria (Nagaraja et al., 1997). Unsaturated fat and monensin could inhibit fiber-degrading bacteria that produce $\mathrm{H}_{2}$. Moreover, the presence of protozoa was expected to decrease the extent of $\mathrm{BH}$ indirectly (incorporation into membranes) or directly (influencing bacterial populations) when unsaturated fat or monensin was fed. Unlike monensin, which should inhibit $\mathrm{H}_{2}$-producing bacteria but not directly inhibit methanogens, bromoethanesulfonate (BES) should inhibit only methanogens (Nagaraja et al., 1997). The hypothesis for this study was that BES, monensin, and unsaturated fat, respectively, would suppress a progressively increasing number of functional groups of microbes and also interact with faunation status, allowing us to evaluate their specific roles quantitatively in ruminal methane and VFA production, NDF digestibility, microbial protein synthesis, and FA composition of the effluent.

\section{MATERIALS AND METHODS}

\section{Experimental Design}

Continuous culture fermenters were adapted as an experimental model to accommodate the intended treatment structure and measurements. Once daily, the fermenters were provided a meal of $40 \mathrm{~g}$ of a $70: 30$ forage:concentrate diet as pellets $(34.5 \% \mathrm{NDF}, 14 \%$ $\mathrm{CP})$ containing either no additive, $5 \%$ animal-vegetable fat, BES (250 $\mu M$ final concentration), or monensin (2.5 $\mu M$ final concentration) in a $4 \times 4$ Latin square design over 4 periods of $23 \mathrm{~d}$ each. At the start of each experimental period, after a priming dose, monensin and BES were continuously infused via buffer to maintain their respective concentrations. The concentration of BES $(250 \mu M)$ was chosen based on pure culture studies by Ungerfeld et al. (2004), in which there was no adaptation of methanogens to BES within $6 \mathrm{~d}$. The concentra- 
tion of monensin was chosen based on dose responses with protozoal cultures (Sylvester et al., 2009) to ensure that monensin did not eliminate protozoa after the initial introduction so that its effect would be limited to bacteria. However, this concentration of monensin was slightly lower than that (approximately $2.9 \mu M$ ) used by Fellner et al. (1997) in continuous culture. Animalvegetable fat (OARDC Feed Mill, Wooster, OH) was added to the basal diet and fed at 5\% (Table 1), which would be considered a maximum amount to depress protozoal counts (Oldick and Firkins, 2000) without inhibiting digestibility. If a more highly unsaturated fat source were fed at $5 \%$ of the diet, we rationalized that the results would not represent potential opportunities in US dairy production resulting from potential depression of DMI or milk fat percentage.

\section{Continuous Culture Operation}

The dual-flow continuous culture system was based on the system described by Hoover et al. (1976). The liquid and solids dilution rates were maintained at 5 and $2 \% / \mathrm{h}$ by regulation of filtrate removal rates and buffer input. On the day of inoculation, ruminal contents were collected through the ruminal fistulae of 2 Holstein cows receiving a diet very similar to our control diet. Ruminal contents were transported to the laboratory in a container maintained at $39^{\circ} \mathrm{C}$, squeezed through 2 layers of cheesecloth, pooled, and used to inoculate the 4 fermenters. Each 23-d experimental period was split into 2 subperiods. In subperiod 1, a multistage filter system (Figure 1) was used on the filter pumps to retain protozoa so that they passed mostly

Table 1. Fatty acid (FA) composition of the control and fatsupplemented diets ${ }^{1}$

\begin{tabular}{lrrr}
\hline & & & Fat-supplemented \\
Item & Control & A-V fat & diet \\
\hline Total FA, \% of DM & 1.94 & 79.70 & 4.59 \\
Individual FA, g/100 g of FA & & & \\
16:0 & 20.21 & 20.28 & 20.27 \\
18:0 & 3.43 & 9.27 & 8.33 \\
Cis-9 18:1 & 18.16 & 37.70 & 34.53 \\
Cis-18:1 & $\mathrm{ND}^{3}$ & 1.38 & 1.16 \\
Trans-11 18:1 & 0.25 & 4.78 & 4.05 \\
Trans-18:1 & $\mathrm{ND}$ & 0.55 & 0.46 \\
18:2n-6 & 42.49 & 24.05 & 27.04 \\
CLA & ND & 0.45 & 0.37 \\
18:3n-3 & 15.47 & 1.54 & 3.80 \\
\hline
\end{tabular}

${ }^{1}$ Control $=70: 30$ forage:concentrate; $\mathrm{A}-\mathrm{V}$ fat = animal-vegetable fat; Fat-supplemented diet $=5 \%$ animal-vegetable fat added to the control diet.

${ }^{2}$ Consisted of cis-11 18:1 and cis-12 18:1.

${ }^{3} \mathrm{ND}=$ not detected.

${ }^{4}$ Consisted of trans-10 18:1, trans-12 18:1, and trans-13 18:1.

${ }^{5}$ Geometrical and positional isomers of conjugated linoleic acid. with the overflow. The filter system consisted of a 50$\mu \mathrm{m}$ filter mounted on a perforated pipette tip, which was then inserted into a $100-\mu \mathrm{m}$ filter mounted on a perforated centrifuge tube. Separation of the 2 filters was necessary to prevent clogging. A layer of polyester fiber prefilter was then used to cover the $100-\mu \mathrm{m}$ filter to prevent it from being clogged by feed particles, and the entire assembly was enclosed in a wire mesh. During the adaptation period, the filters were changed whenever they were blocked, as evidenced by the presence of gas bubbles in the filtrate pump tubing or when filtrate rates were less than those expected. However, toward the end of the adaptation period, the filters remained unblocked over the 24 -h feeding cycle. After $7 \mathrm{~d}$ of adaptation, the fermenters were sampled for 3 d. At the start of subperiod 2, filters were replaced by single-piece conventional filters, which were made of a wire mesh of 300- $\mu \mathrm{m}$ pore size attached to the end of a cut pipette tip (panel D in Figure 1) to allow protozoa to efflux to negligible numbers over $3 \mathrm{~d}$ and to prevent protozoal recovery; after a further $7 \mathrm{~d}$ of adaptation, the fermenters were sampled for $3 \mathrm{~d}$. Volumes of the 4 fermenters were between 1600 and $1800 \mathrm{~mL}$. The $\mathrm{pH}$ in the fermenters was not adjusted but varied between 6.2 and 6.7 over the feeding cycle. Agitation was set at 50 $\mathrm{rpm}$, and temperature was maintained at $39^{\circ} \mathrm{C}$. Flow rates were determined by weighing the solid and liquid effluents once a day during the adaptation period and were adjusted as required to keep them constant during the entire faunated and defaunated subperiods.

\section{Sample Collection and Analysis}

Total daily effluent on $\mathrm{d} 8,9$, and 10 in each subperiod was collected overnight on ice, and a sample of the effluent (20\%) was composited by fermenter for analysis. Freeze-dried effluent samples were analyzed for $\mathrm{N}$ using the Kjeldahl method (AOAC, 1990) and for NDF in the presence of heat-stable amylase and sodium sulfite (Van Soest et al., 1991). The FA in the freeze-dried effluent samples were methylated and analyzed by GLC (Ribeiro et al., 2005). The BH of FA was calculated as described by $\mathrm{Wu}$ et al. (1991). A 47-mL aliquot of the composited effluent was acidified using $3 \mathrm{~mL}$ of 6 $N \mathrm{HCl}$ before analysis for $\mathrm{VFA}, \mathrm{NH}_{3}-\mathrm{N}$, and lactate. Volatile FA were determined by GLC (Harvatine et al., 2002). Ammonia was determined using the colorimetric method of Chaney and Marbach (1962). Additionally, L-lactate was determined with a kit for a colorimetric procedure using lactate oxidase (Pointe Scientific Inc., Canton, MI). An aliquot of the effluent sample and the fermenter contents was fixed in formalin, and protozoal counts were determined by microscopy (Dehority, 1993; Oldick and Firkins, 2000). The protozoal counts were 
A

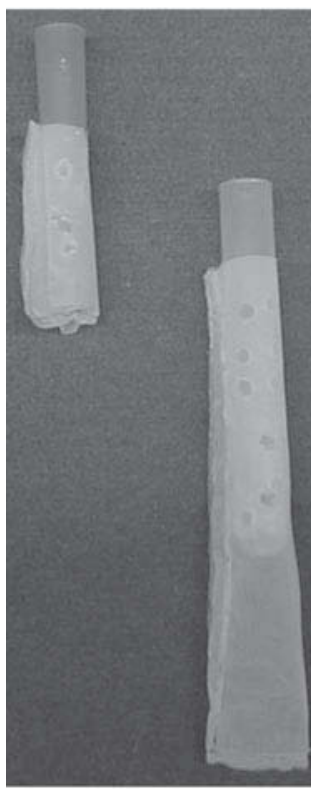

B

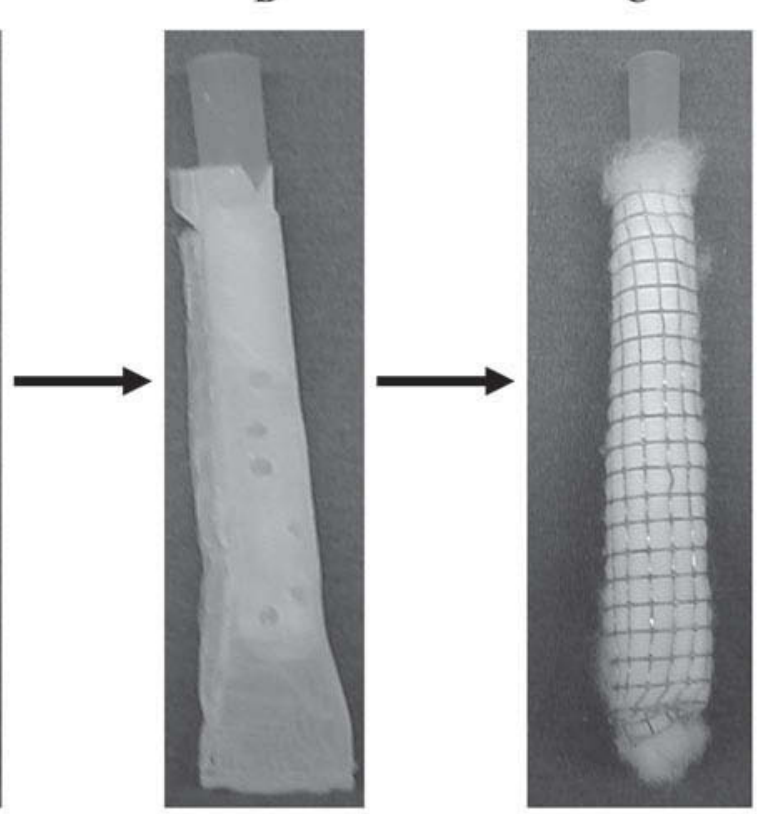

D

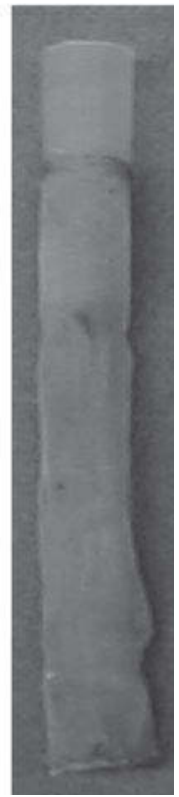

Figure 1. Assembly of the multistage filter. The $50-\mu \mathrm{m}$ filter is mounted on a perforated pipette tip and the 100- $\mu \mathrm{m}$ filter is mounted on a perforated centrifuge tube (panel A). The $50-\mu \mathrm{m}$ filter is inserted into the tube with the $100-\mu \mathrm{m}$ filter (panel B). This assembly is enclosed in a layer of polyester fiber prefilter and enclosed in wire mesh (panel C). The traditional filter with a pore size of 300- $\mu \mathrm{m}$ is shown in panel D.

used to calculate the generation times of protozoa according to the following formula: generation time in hours $=$ total pool size of cells in fermenter/flow of cells in effluent per hour (Sylvester et al., 2004). The total outflow of cells was multiplied by the N:cell ratio, which was determined by recovering virtually all protozoa in a known volume by using a series of centrifugation and filtration steps and determining the mass of DM and $\mathrm{N}$ of that filtrate (Sylvester et al., 2005). After analysis of purine concentration of that filtrate (Ushida et al., 1985; Zinn and Owens, 1986), total effluent purines were corrected for protozoal purines and multiplied by the $\mathrm{N}$ :purine ratio of bacterial samples.

During the sampling period, after feeding, the headspace in the fermenters was flushed with $\mathrm{CO}_{2}$, and after checking by using a soap solution to ensure there were no leaks, special gas-impermeable bags were attached for gas collection. Total gas samples from the headspace were collected for $24 \mathrm{~h}$ from the fermenters on the 3 sampling days and used for methane analyses by GLC. Gastight syringes were used to inject standards and a known volume of gas from the bags in triplicate, and gas content was determined using a $5890 \mathrm{HP}$ gas chromatograph with an HP PlotQ capillary column (30 $\mathrm{m} \times 530 \mu \mathrm{m}$ i.d.) with a $40-\mu \mathrm{m}$ film thickness. The volume of gas in the bags was estimated by measuring water displaced when the gas from balloons was dispersed into an airtight graduated container, and this volume of gas per day was multiplied by $\mathrm{CH}_{4}$ concentration to yield $\mathrm{CH}_{4}$ production rates.

\section{Statistical Analysis}

Data were analyzed using the MIXED procedure (SAS Institute, 1999) according to the following model:

$$
\mathrm{Y}_{\mathrm{ijkl}}=\mu+\mathrm{f}_{\mathrm{i}}+\mathrm{P}_{\mathrm{j}}+\mathrm{T}_{\mathrm{k}}+\mathrm{D}_{\mathrm{l}}+\left(\mathrm{T} \times \mathrm{D}_{\mathrm{kl}}\right)+\mathrm{e}_{\mathrm{ijk} \mathrm{l}},
$$

where $Y_{i j k l}$ is the dependent, continuous variable, $\mu$ is the overall population mean, $\mathrm{f}_{\mathrm{i}}$ is the random effect of the ith fermenter $(\mathrm{i}=1,2,3,4), \mathrm{P}_{\mathrm{j}}$ is the fixed effect of the $\mathrm{jth}$ period $(\mathrm{j}=1,2,3,4), \mathrm{T}_{\mathrm{k}}$ is the fixed effect of the kth treatment $(\mathrm{k}=1,2,3,4), \mathrm{D}_{1}$ is the fixed effect of the lth filter status $(l=1,2)$, and $\mathrm{e}_{\mathrm{ijk}}$ is the residual error, assumed independent and $\sim \mathrm{N}\left(0, \sigma_{\mathrm{e}}^{2}\right)$.

When there was no interaction, the effects of treatment were averaged over faunation status, and main effect means of treatments were evaluated using a protected least significant difference. When there was an interaction of treatment and faunation status, simple means were separated by a protected least significant difference. The authors recognize the increased likelihood for type I error when separating 8 treatment means, but the reduction of $\mathrm{n}$ to 4 also increased the risk for type II error. We reasoned that the least significant difference test restricted inferences to be within the 
Table 2. Main effects for counts and generation time of mixed protozoa in the faunated subperiod of continuous cultures provided the control, fat, monensin, or BES treatments ${ }^{1}$

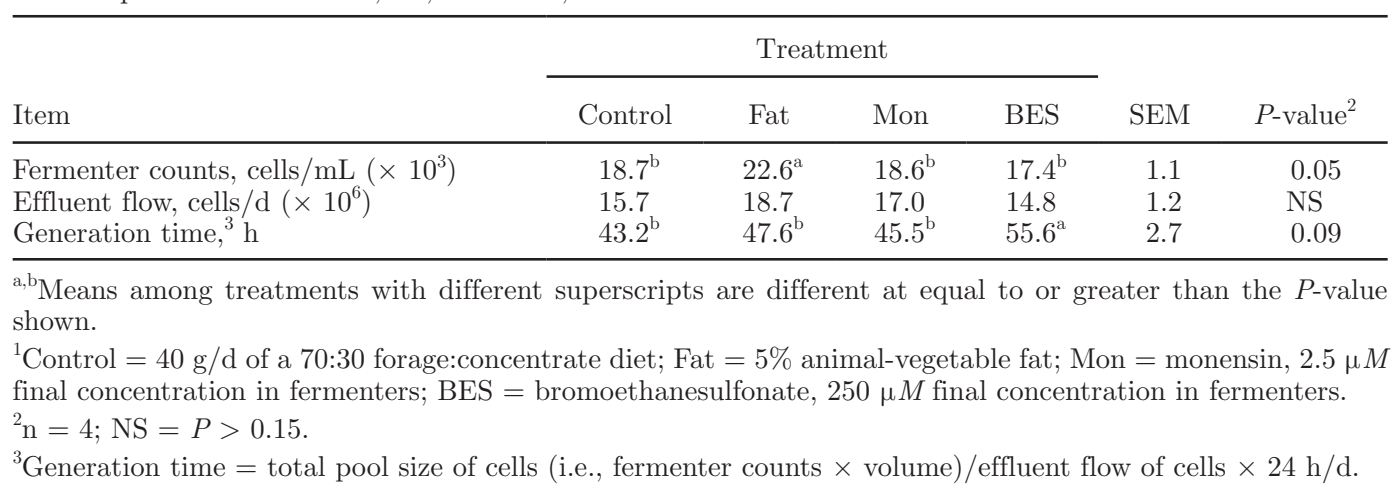

context of explaining interactions among main effects for FA flows, which were largely a result of a priori expectations for fat treatments to change with faunation status. Moreover, the more conservative Tukey test did not alter any statistical inferences.

\section{RESULTS AND DISCUSSION}

\section{Protozoal Counts and Generation Time}

The potential long-term effects of continuous culture have not been well studied, although fermentation, digestibility, and prokaryotic populations are comparable enough to the animal (Ziemer et al., 2000) for our purposes. The residual effects of chemical defaunation agents on bacterial populations (Hristov and Jouany, 2005) justify our approach and, along with a tendency for persistent differences in bacterial (Weimer et al., 2008) and protozoal (Sylvester et al., 2005) populations among animals regardless of diet, argue for a long-term stability of populations after adjustment to culture.

A diverse protozoal population including isotrichids was established in the modified continuous culture system (Karnati et al., 2009). Total protozoal counts in the fermenters were highest $(P=0.05)$ for the $5 \%$ added fat diet and were similar for the other 3 diets, but the effluent flow of cells per day was not affected by treatment (Table 2). The counts (average $=19.3 \times$ $10^{3} / \mathrm{mL}$ ) were approximately 50 - to 100 -fold lower than those observed in vivo, but when expressed on the basis of available substrate concentration in the fermenters, they more closely approximated in vivo conditions. Our counts were approximately 5 -fold lower than those of Hoover et al. (1976) in continuous culture, but the amount of feed supplied in their experiment was about twice ours. Generation time adjusted rapidly to approximate the transfer interval for 4 representative protozoal cultures, probably allowing protozoa to optimize their biomass through control of their cell cycle relative to substrate availability over the feeding cycle (Sylvester et al., 2009). We therefore expected that protozoal generation time (average $=48 \mathrm{~h}$ ) would approximate their retention time $(50 \mathrm{~h})$ in the fermenters. In fact, protozoal counts were highest (Table 2) on the $5 \%$ added fat diet. The direct incorporation of preformed FA might have spared more energy for cell growth. Another potential explanation is that $\mathrm{BH}$ would have decreased the toxic concentrations of FA below a threshold for most of the 24-h feeding interval, so energy-sensing signals [unknown at present but discussed by Sylvester et al. (2009)] might have compensated for short-term inhibition by fat to maintain protozoal growth under the current conditions of slower turnover pressure. There was a trend $(P=0.09)$ for increased protozoal generation times for the BES treatment compared with the fat, monensin, and control treatments. Because BES should not affect protozoa directly (Nagaraja et al., 1997) but appeared to depress archaeal populations associated with protozoa in the current study (Karnati et al., 2009), there could have been an interruption in the interspecies hydrogen transfer and a depression in ATP yield by protozoa that slowed their growth rate.

\section{Digestibility of Nutrients}

The digestibilities of NDF and OM were not affected by treatment, and there was no interaction with faunation status $(P>0.15$; data not shown). However, defaunation increased $(P<0.05)$ apparent $\mathrm{OM}$ and NDF digestibilities in the fermenters (Table 3). In a quantitative meta-analysis of the effects of defaunation on ruminal digestibility, Eugène et al. (2004) observed that $\mathrm{OM}$ and cell wall digestibilities were significantly decreased by defaunation. However, in $64 \%$ of the in vivo studies included in that meta-analysis, defaunation was achieved by the use of detergents and chemicals, which could potentially lead to residual effects on bacteria in the defaunated period (Hristov and Jouany, 
Table 3. Main effect means of treatment and faunation status on NDF and $\mathrm{OM}$ digestibilities, $\mathrm{NH}_{3}-\mathrm{N}$, and $\mathrm{N}$ flows in continuous culture ${ }^{1}$

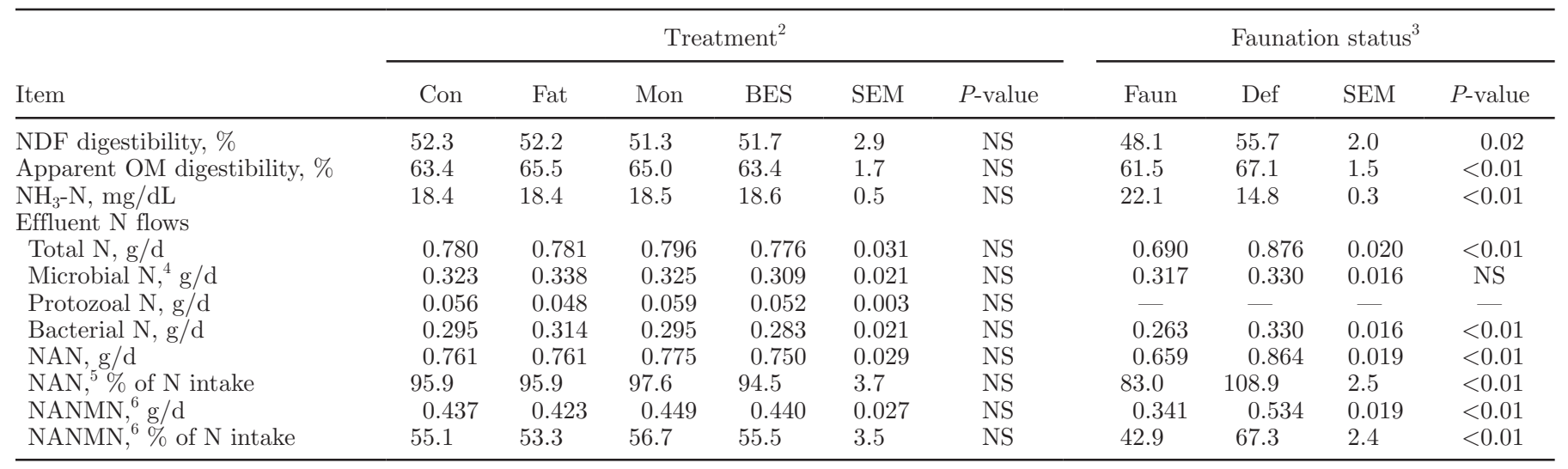

${ }^{1}$ There were no interactions of treatment with faunated status $(P>0.15)$.

${ }^{2} \mathrm{Con}=40 \mathrm{~g} / \mathrm{d}$ of a $70: 30$ forage:concentrate diet; Fat $=5 \%$ animal-vegetable fat; Mon $=$ monensin, $2.5 \mu M$ final concentration in fermenters; $\mathrm{BES}=$ bromoethanesulfonate, $250 \mu M$ final concentration in fermenters. Means are averaged over the faunation periods; $\mathrm{n}=8$ except for protozoal N $(\mathrm{n}=4)$. NS $=P>0.15$.

${ }^{3}$ Faun $=$ faunated subperiod; Def $=$ defaunated subperiod. Means are averaged over treatments, $\mathrm{n}=16 . \mathrm{NS}=P>0.15$.

${ }^{4}$ Microbial $\mathrm{N}$ includes both bacterial and protozoal $\mathrm{N}$ for the faunated subperiod but only bacterial $\mathrm{N}$ in the defaunated subperiod.

${ }^{5} \mathrm{~N}$ intake was from feed and did not include $\mathrm{N}$ intake from buffer.

${ }^{6} \mathrm{NANMN}=$ nonammonia nonmicrobial $\mathrm{N}$.

2005). Total culturable and cellulolytic bacterial numbers and ruminal OM digestibility were not affected by defaunation (Koenig et al., 2000). However, in the same study, refaunation of sheep decreased cellulolytic bacterial numbers, suggesting preferential protozoal predation of cellulolytic bacteria. In contrast to results from defaunated cattle, when unfaunated (separated at birth) animals were compared with faunated animals, the $16 \mathrm{~S}$ rDNA copies of Ruminococcus albus and Ruminococcus flavefaciens were 3.5 and 2.0 times higher, respectively, but Fibrobacter succinogenes was 2.4 times lower in the unfaunated animals (Ozutsumi et al., 2006). Although protozoa have fibrolytic enzymes, their activities toward substrates are probably lower than those in fibrolytic bacteria, yet the presence of protozoa in vivo should improve NDF digestibility indirectly by quenching oxygen, helping to prevent declines in ruminal $\mathrm{pH}$, and potentially providing a more steady supply of growth factors to optimize conditions for fibrolytic bacteria (Firkins and $\mathrm{Yu}, 2006$ ). The net benefits of protozoa on NDF digestibility probably are diet dependent. In the review by Eugène et al. (2004), protozoa did not contribute significantly to the maintenance of $\mathrm{pH}$ when the diets contained less then $50 \%$ concentrate (as was the case in our fermenters). Moreover, in our study, the headspace in the fermenters was flushed daily with $\mathrm{CO}_{2}$ during the collection period, further minimizing the beneficial role of protozoa in oxygen quenching. The lack of protozoal predation in our defaunated cultures might have allowed greater proliferation of cellulolytic bacteria and greater NDF digestibility than in the faunated subperiod with less indirect benefit resulting from the presence of protozoa compared with in vivo conditions (Firkins and Yu, 2006).

\section{N Flows and $\mathrm{NH}_{3}$ Concentration}

Total $\mathrm{N}$ flow was increased $(P<0.05)$ by defaunation but was not affected by treatment (Table 3 ). The $\mathrm{NH}_{3}-\mathrm{N}$ concentrations in the fermenters were not different among the 4 treatments but were decreased $(P$ $<0.05)$ by defaunation, which would be expected because of decreased proteolysis or deamination (Walker et al., 2005). The increased digestibility of NDF in the defaunated subperiod probably also provided additional energy for uptake and incorporation of $\mathrm{NH}_{3}$ for synthesis of bacterial protein, also decreasing $\mathrm{NH}_{3}-\mathrm{N}$ concentration. Defaunation decreased ruminal $\mathrm{NH}_{3}-\mathrm{N}$ concentrations in 75 trials (Eugène et al., 2004) and increased the duodenal flow of microbial $\mathrm{N}$ by $12 \%$, on average. The flow of microbial $\mathrm{N}$ (bacterial N plus protozoal $\mathrm{N}$ in the faunated subperiod) was not affected by treatment or faunation status (Table 3). However, the flow of bacterial $\mathrm{N}$ was greater $(P<0.05)$ in the defaunated subperiod. Protozoal predation and competition for substrate limits the numbers of bacteria in the rumen; therefore, defaunation is usually associated with an increase in total bacterial numbers (Dehority, 2003). However, despite the consistent increase in efficiency of microbial $\mathrm{N}$ synthesis, the increase in microbial $\mathrm{N}$ flow to the duodenum appears to be much less, and if it is at the expense of decreased NDF digestibility, the benefit 
Table 4. Main effects of fermentation products in faunated and defaunated continuous culture fermenters provided control, fat, monensin, or BES treatments ${ }^{1}$

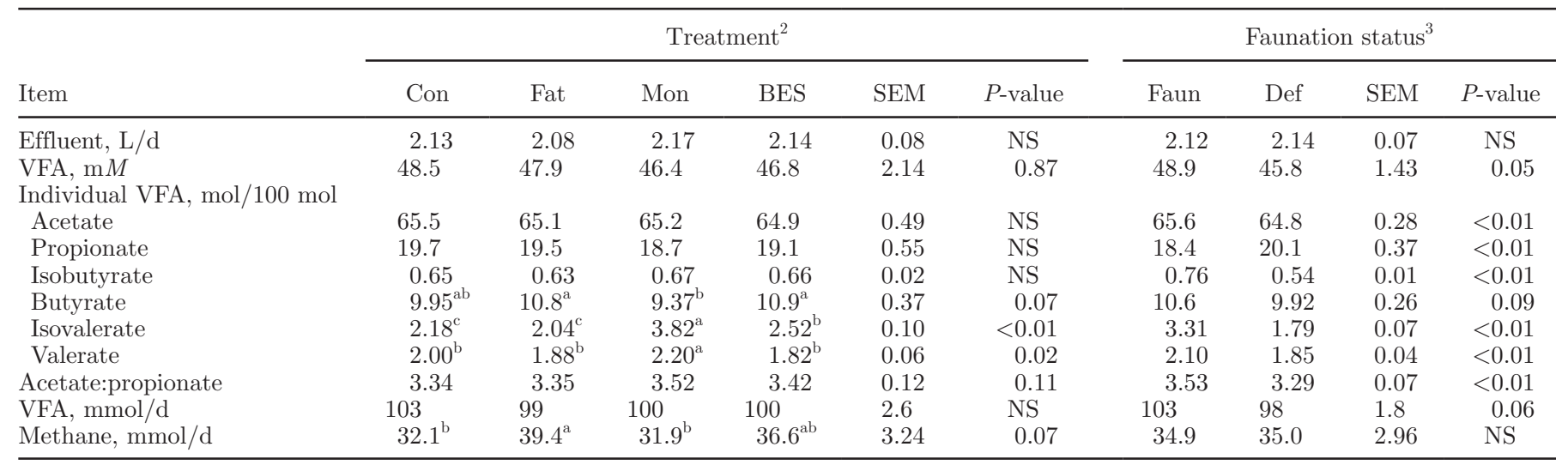

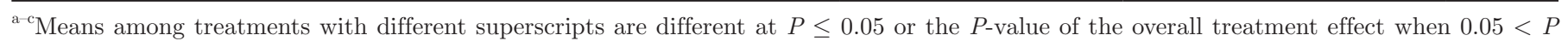
$\leq 0.10$.

${ }^{1}$ There were no interactions of treatment with faunated status $(P>0.15)$.

${ }^{2} \mathrm{Con}=40 \mathrm{~g} / \mathrm{d}$ of a 70:30 forage:concentrate diet; Fat $=5 \%$ animal-vegetable fat; Mon $=$ monensin, $2.5 \mu M$ final concentration in fermenters; $\mathrm{BES}=$ bromoethanesulfonate, $250 \mu M$ final concentration in fermenters. Means are averaged over the faunation periods; $\mathrm{n}=8$. NS $=P>$ 0.15 .

${ }^{3}$ Faun $=$ faunated subperiod; Def $=$ defaunated subperiod. Means are averaged over treatments; $\mathrm{n}=16 . \mathrm{NS}=P>0.15$.

to the dairy cow by defaunation is lessened (Firkins et al., 2007). Treatment had no effect (Table 3), but defaunation increased $(P<0.05)$ effluent flows of NAN and nonammonia-nonmicrobial $\mathrm{N}$, which is an estimate of RUP. As explained previously, protozoa contribute extensively to ruminal proteolysis (Walker et al., 2005). However, these responses perhaps are magnified in the fermenter system because grinding and stirring probably predisposes more small particles to passage with the fluid phase than occurs in the rumen, and the larger screen size in the defaunated subperiod might have allowed greater efflux of nonammonia-nonmicrobial N than in the faunated subperiod.

\section{VFA}

Defaunation decreased total VFA concentration, acetate:propionate ratio, and acetate, isovalerate, valerate, and isobutyrate molar percentages while increasing molar percentage of propionate compared with the main effect of the faunated subperiod $(P<0.05$, effect of faunation status; Table 4). Butyrate molar percentage and total VFA production tended $(P<0.09)$ to be lower for the defaunated subperiod. The lack of difference $(P>0.20)$ among treatments for liquid flow rates (data not shown) confirmed these treatment responses for VFA. Lower VFA production for defaunated subperiods is likely a result of increased de novo FA synthesis (see later discussion). Protozoa are known to contribute substantially to butyrate production in the rumen (Eugène et al., 2004), perhaps because they ferment lactate to butyrate (Williams and Coleman, 1997). Lactate concentrations in the effluent were undetectable (data not shown). The effects of defaunation on molar proportions of VFA were similar to those found by Abel et al. (2006) when they compared grass hay and cereal grain mixtures in faunated or defaunated Rusitec fermenters.

Monensin increased the molar proportions of isovalerate and valerate but not other VFA. There was a trend for a decrease $(P<0.07)$ in the molar proportion of butyrate with monensin. Ipharraguerre and Clark (2003) reviewed the effects of feeding monensin to lactating dairy cows and reported that monensin usually increased the molar proportion of propionate and decreased acetate:propionate ratio. However, Jenkins et al. (2003) reported that feeding monensin to fermenters increased molar proportions of acetate and propionate but decreased acetate:propionate ratio and the molar proportion of butyrate. The addition of monensin (2.9 $\mu M$ of fermenter contents) decreased the molar percentage of acetate and increased the molar percentage of propionate, decreasing the ratio of acetate to propionate from 3.0 to 1.7 (Fellner et al., 1997). In their study, isovalerate proportion decreased, which is in contrast with our results. Although valerate and isovalerate result from the breakdown of AA (Nagaraja et al., 1997) and monensin inhibits deaminating bacteria (Walker et al., 2005), concentration differences also could reflect differences in uptake of these VFA. Moreover, valerate concentration can increase with increasing provision of sugars (Hall and Weimer, 2007) 
and sometimes increases in the presence of monensin, potentially because Megasphaera elsdenii is fermenting lactate to this highly reduced end product (Nagaraja and Titgemeyer, 2007).

Based on largely pure culture studies, monensin has traditionally been thought to select for gram-negative bacteria such as Megasphaera, Prevotella, and Fibrobacter, which produce more propionate and succinate, and isovalerate is a major fermentation end product of some strains of these organisms (Stewart et al., 1997). However, recent work in vivo indicated a relative increase in Prevotella but a decrease in Megasphaera with monensin (Weimer et al., 2008). In addition, pure cultures that produce lactate (e.g., Streptococcus bovis) are sensitive to monensin, but bacteria that utilize this acid (e.g., M. elsdenii and Selenomonas ruminantium) are less sensitive, further converting any lactate to propionate and butyrate (Ipharraguerre and Clark, 2003) or potentially shifting their niche toward glucose use if monensin inhibits lactate producers (Nagaraja and Titgemeyer, 2007). However, the relative abundance of $S$. bovis was not affected in dairy cows (Weimer et al., 2008). As documented by these authors, further research on microbial ecosystems is needed to assess effects of varying dosages of monensin in dairy cows, particularly given adaptive mechanisms by gram-positive bacteria to produce extracellular polysaccharides to prevent diffusion of monensin to the cell wall and because the majority of bacteria in the rumen have not yet been cultured.

\section{Methane Production}

In general, defaunation is expected to decrease methane production by approximately 15\% (Hegarty, 1999) by removal of ecto- and endosymbionts. Defaunation did not decrease methane production in the fermenters (Table 4). Consistent with our results, defaunation did not decrease methane production in sheep fed a $60 \%$ forage diet (Dohme et al., 2001). When compared with higher grain diets, when fed a high-forage diet such as that in the current study (70:30 forage:concentrate), defaunation was less likely to affect methane production (Hegarty, 1999), and defaunation decreased methane production the most for fermenters fed $66 \%$ concentrate diets (Abel et al., 2006). Conversely, unsaturated fat increased protozoal counts (Table 2) and methane production (Table 4). However, there was no interaction with faunation status (i.e., a consistently high methane production for the fat treatment), so this relationship seems to be independent of protozoa. Protozoa engulf starch rapidly and also consume lactate, thereby keeping the ruminal $\mathrm{pH}$ from becoming more acidic (Williams and Coleman, 1997). In addition to their numbers being inversely correlated with ruminal pH in beef cattle (Nagaraja and Titgemeyer, 2007), lower $\mathrm{pH}$ was suggested to have a major inhibitory effect on methanogens (Brown et al., 2006). Because both methanogens and protozoa are sensitive to low $\mathrm{pH}$, protozoa might protect methanogens by helping to prevent declines in ruminal $\mathrm{pH}$. In our study, feeding rate was adjusted to keep $\mathrm{pH}$ from declining low enough to be inhibitory to these populations, whereas high-concentrate diets might enhance the effectiveness of fat sources to suppress protozoal populations (Firkins, 1996; Firkins et al., 2007).

Bromoethanesulfonate inhibited methane synthesis completely on d 1 and 2 of treatment, but methane production was detected as early as d 3 (data not shown). When pure cultures of the typical rumen methanogens Methanobrevibacter ruminantium, Methanosarcina mazeii, and Methanomicrobium mobile were administered BES $(250 \mu M)$, methane production was inhibited for $6 \mathrm{~d}$ without any adaptation (Ungerfeld et al., 2004). These authors discussed the potential degradation of BES by mixed ruminal microbiota, which might have decreased its inhibitory effect on the methanogens in the fermenters, or our BES treatment could have selected for nonsusceptible methanogens.

Compared with the control, monensin did not decrease methane production. When $25 \mathrm{ppm}$ of monensin $(0.7 \mu M)$ was fed in continuous culture (Jenkins et al., 2003), methane production was decreased and molar proportions of propionate and valerate were increased, but isovalerate was not affected. The synthesis of reduced VFA such as propionate and valerate might have provided another route for the disposal of reducing equivalents in their study, and $\mathrm{pH}$ was actually decreased with monensin, further exacerbating responses. Although BH uses metabolic hydrogen, BH probably plays only a minor role in reducing methane emissions (Johnson and Johnson, 1995), so we have no explanation for the trend $(P=0.07)$ for an increase in methane production by the fat treatment.

\section{Effluent Flow and Biohydrogenation of FA}

Flows of 18:0 were greater $(P<0.01)$ for the fat treatment but were not affected by or did not interact with faunation status (Table 5). Flows of cis-9 18:1, trans-10 18:1, trans-11 18:1, and cis-9, cis-12 18:2 all had faunation status $\times$ treatment interactions $(P<$ $0.05)$ that were explained primarily by the lack of difference among all treatments except for fat, regardless of faunation status, but with flows all being increased when fat was fed in the defaunated subperiod compared with the faunated subperiod. Flows of conjugated linoleic acid $($ CLA $)$ were greater $(P<0.05)$ for the main 
about 6\% Diplodiniinae (Karnati et al., 2009). These fibrolytic protozoa might engulf more lipid adsorbed to or part of particulate matter and thereby slow their $\mathrm{BH}$ (Yáñez-Ruiz et al., 2006), whereas Jenkins et al. (2008) have argued that trans-11 18:1 and CLA might be preferentially incorporated into protozoa through predation of bacteria. The slow turnover rate of particulates in our continuous cultures should have allowed a more extensive BH by bacteria (Qiu et al., 2004), and the slower growth rate of protozoa might have decreased the rate of incorporation of FA into membranes compared with expectations in vivo. Bacterial $\mathrm{N}$ production increased during the defaunated subperiod (Table 3). Use of VFA carbon for de novo FA synthesis therefore explains why the VFA production in the defaunated fermenters was lower (Table 4), despite a higher NDF and apparent OM digestibility (Table 3). Presumably, in the faunated subperiod, a greater accumulation of preformed FA from the fat diet was being incorporated into protozoa, whereas in the defaunated subperiod, the loss of protozoal biomass diminished the incorporation of dietary FA, but the increased bacterial biomass increased flow of total FA and many individual isomers as a result of an overall net synthesis. In this regard, bacterial lipids have a relatively high concentration (approximately $5 \mathrm{~g} / 100 \mathrm{~g}$ ) of trans-11 18:1 compared with other isomers except for 16:0 and 18:0, particularly with higher forage:concentrate ratios reflective of those in our experiment (Vlaeminck et al., 2006).

There were no interactions among faunation status and treatment for $\mathrm{BH}$ (Table 5). Defaunation decreased $(P<0.05)$ the $\mathrm{BH}$ of total $\mathrm{C}_{18} \mathrm{FA}$ and the $\mathrm{BH}$ of oleic, linoleic, and linolenic acids. The BH of cis-9 18:1 was greater $(P<0.08)$ but that for $18: 3$ n-3 was lower $(P$ $<0.05)$ for the main effects of the fat treatment versus the other diets. Because oleic acid was much higher but linolenic acid was much lower in the supplemental fat and primarily from the alfalfa pellets (Table 1), the addition of animal-vegetable fat might have interfered with $\mathrm{BH}$ of $18: 3 \mathrm{n}-3$.

Because of the central role of VA in biohydrogenation (Jenkins et al., 2008), the flows of VA were expressed as ratios to account for differing flows of total and individual FA for faunation status (Table 5). The VA:unsaturated FA ratio was greater $(P<0.01)$ for the main effect means of faunated versus defaunated subperiods and also for fat compared with other treatments. The VA:trans-10 18:1 ratio had an interaction explained by the lowest ratio for the fat treatment, regardless of faunation status, whereas the presence of protozoa increased this ratio for the nonfat treatments. Unfortunately, the specific bacteria responsible for trans-10 18:1 production remain elusive (Maia et al., 2007; Paillard et al., 2007). However, increasing fat supplementation seems to increase trans-10 18:1 formation compared with fat from basal sources, whereas results for this ratio also support protozoa as a vehicle for preferential VA incorporation and therefore increasing this ratio of VA:trans-10 18:1. The VA:stearic acid ratio also had a faunation $\times$ treatment interaction $(P$ $<0.01)$. This ratio was highest for the fat treatment in the defaunated subperiods. Because the VA:stearic acid ratio in bacteria was $<0.1$ (Vlaeminck et al., 2006), this increased ratio supported a less complete $\mathrm{BH}$ process when protozoa were removed. Because protozoa do not contribute to $\mathrm{BH}$ directly and apparently incorporate VA preferentially, such a response among treatments would be indicative of changes in BH activity or populations of lipid-metabolizing bacteria. Solids-associated bacteria typically have higher concentrations of VA than liquid-associated bacteria (Vlaeminck et al., 2006), and protozoa might selectively predate the latter (Williams and Coleman, 1992). Moreover, defaunation influences the population structure of bacteria (Yáñez-Ruiz et al., 2007), including those active in FA metabolism, as described in our companion study (Karnati et al., 2009).

Monensin had no effect on the flow of trans-10 18:1 from the fermenters. Higher concentrations of trans-10 18:1 are highly correlated with the depression of milk fat synthesis (Shingfield et al., 2006), which can be exacerbated in diets with increasing concentrations of unsaturated fat and NSC when monensin is added (Oelker et al., 2009). Perhaps the longer turnover time or the animal-vegetable fat used in our study prevented an effect of monensin.

\section{CONCLUSIONS}

Defaunation increased outflow of feed NAN and increased NDF digestibility but not microbial $\mathrm{N}$ flow, decreased acetate:propionate ratio, and decreased the ratio of trans-11 to trans-10 18:1 isomers without affecting methane production. Under our conditions, monensin changed molar proportions of isovalerate and valerate but not acetate:propionate and had no effects on other measurements. Bromoethanesulfonate did not affect methane production but increased the generation time of protozoa. Analysis of the microbial populations in the fermenters in our companion paper helps integrate the changes in fermentation and $\mathrm{BH}$ associated with defaunation. Because of challenges in defaunation in vivo, our modified system should advance our understanding of protozoal ecology.

\section{ACKNOWLEDGMENTS}

The authors express their appreciation to William Hoover for his helpful discussions and insight in adapt- 
ing our fermenter system for this project. Moreover, we are thankful for the help of Lynn Willett in methane analyses.

\section{REFERENCES}

Abel, H., B. Schröder, P. Lebzien, and G. Flachowsky. 2006. Effect of defaunation on fermentation characteristics and biotin balance in an artificial rumen-simulation system (RUSITEC) receiving diets with different amounts and types of cereal. Br. J. Nutr. 95:99-104.

AOAC. 1990. Official Methods of Analysis. 15th ed. AOAC Int. Arlington, VA.

Beauchemin, K. A., M. Kreuzer, F. O. O'Mara, and T. A. McAllister. 2008. Nutritional management for enteric methane abatement: A review. Aust. J. Exp. Agric. 48:21-27.

Boeckaert, C., V. Fievez, D. Van Heck, W. Verstraete, and N. Boon. 2007. Changes in rumen biohydrogenation intermediates and ciliate protozoa diversity after algae supplementation to dairy cattle. Eur. J. Lipid Sci. Technol. 109:767-777.

Brown, M. S., C. H. Ponce, and R. Pulikanti. 2006. Adaptation of beef cattle to high-concentrate diets: Performance and ruminal metabolism. J. Anim. Sci. 84(E Suppl.):E25-E33.

Chaney, A. L., and E. P. Marbach. 1962. Modified reagents for determination of urea and ammonia. Clin. Chem. 8:130-132.

Cotta, M., and R. Forster. 2006. The family Lachnospiraceae, including the genera Butyrivibrio, Lachnospira and Roseburia. Prokaryotes 4:1002-1021.

Dehority, B. A. 1993. Laboratory Manual for Classification and Morphology of Rumen Ciliate Protozoa. CRC Press Inc., Boca Raton, FL.

Dehority, B. A. 2003. Rumen Microbiology. Nottingham University Press, Nottingham, UK.

Devillard, E., F. M. McIntosh, C. J. Newbold, and R. J. Wallace. 2006. Rumen ciliate protozoa contain high concentrations of conjugated linoleic acids and vaccenic acid, yet do not hydrogenate linoleic acid or desaturate stearic acid. Br. J. Nutr. 96:697-704.

Dohme, F., A. Machmüller, A. Wasserfallen, and M. Kreuzer. 2001. Ruminal methanogenesis as influenced by individual fatty acids supplemented to complete ruminant diets. Lett. Appl. Microbiol. $32: 47-51$.

Eugène, M., H. Archimède, and D. Sauvant. 2004. Quantitative metaanalysis on the effects of defaunation of the rumen on growth, intake and digestion in ruminants. Livest. Prod. Sci. 85:81-97.

Fellner, V., F. D. Sauer, and J. K. G. Kramer. 1997. Effect of nigericin, monensin, and tetronasin on biohydrogenation in continuous flowthrough ruminal fermenters. J. Dairy Sci. 80:921-928.

Firkins, J. L. 1996. Maximizing microbial protein synthesis in the rumen. J. Nutr. 126:1347S-1354S.

Firkins, J. L., A. N. Hristov, M. B. Hall, G. A. Varga, and N. R. StPierre. 2006. Integration of ruminal metabolism in dairy cattle. J. Dairy Sci. 89(E Suppl.):E31-E51.

Firkins, J. L., S. K. R. Karnati, and Z. Yu. 2008. Linking rumen function to animal response by application of metagenomics techniques. Aust. J. Exp. Agric. 48:711-721.

Firkins, J. L., and Z. Yu. 2006. Characterisation and quantification of the microbial populations in the rumen. Pages 19-54 in Ruminant Physiology, Digestion, Metabolism and Impact of Nutrition on Gene Expression, Immunology and Stress. K. Sejrsen, T. Hvelplund, and M. O. Nielsen, ed. Wageningen Academic Publishers, Wageningen, the Netherlands.

Firkins, J. L., Z. Yu, and M. Morrison. 2007. Ruminal nitrogen metabolism: Perspectives for integration of microbiology and nutrition for dairy. J. Dairy Sci. 90(E Suppl.):E1-E16.

Hall, M. B., and P. J. Weimer. 2007. Sucrose concentration alters fermentation kinetics, products, and carbon fates during in vitro fermentation with mixed ruminal microbes. J. Anim. Sci. 85:1467-1478.
Harfoot, C. G., and G. P. Hazlewood. 1997. Lipid metabolism in the rumen. Pages 382-426 in The Rumen Microbial Ecosystem. P. N. Hobson and C. S. Stewart, ed. Blackie Academic and Professional, New York, NY.

Harvatine, D. I., J. E. Winkler, M. Devant-Guille, J. L. Firkins, N. R. St-Pierre, and M. L. Eastridge. 2002. Whole linted cottonseed as a forage substitute: Fiber effectiveness and digestion kinetics. J. Dairy Sci. 85:1988-1999.

Hegarty, R. S. 1999. Reducing rumen methane emissions through elimination of rumen protozoa. Aust. J. Agric. Res. 50:13211327.

Hoover, W. H., B. A. Crooker, and C. J. Sniffen. 1976. Effects of differential solid-liquid removal rates on protozoa numbers in continuous cultures of rumen contents. J. Anim. Sci. 43:528534.

Hristov, A. N., and J.-P. Jouany. 2005. Factors affecting the efficiency of nitrogen utilization in the rumen. Pages 117-166 in Nitrogen and Phosphorus Nutrition of Cattle and Environment. A. N. Hristov and E. Pfeffer, ed. CAB International, Wallingford, UK.

Ipharraguerre, I. R., and J. H. Clark. 2003. Usefulness of ionophores for lactating dairy cows: A review. Anim. Feed Sci. Technol. 106:39-57.

Jenkins, T. C., V. Fellner, and R. K. McGuffey. 2003. Monensin by fat interactions on trans fatty acids in cultures of mixed ruminal microorganisms grown in continuous fermenters fed corn or barley. J. Dairy Sci. 86:324-330.

Jenkins, T. C., R. J. Wallace, P. J. Moate, and E. E. Mosley. 2008. Board-Invited Review: Recent advances in biohydrogenation of unsaturated fatty acids within the rumen microbial ecosystem. J. Anim. Sci. 86:397-412.

Johnson, K. A., and D. E. Johnson. 1995. Methane emissions from cattle. J. Anim. Sci. 73:957-963.

Karnati, S. K. R., Z. Yu, and J. L. Firkins. 2009. Investigating unsaturated fat, monensin, or bromoethanesulfonate in continuous cultures retaining ruminal protozoa. II. Interaction of treatment and presence of protozoa on prokaryotic communities. J. Dairy Sci. 92:3861-3873.

Koenig, K. M., C. J. Newbold, F. M. McIntosh, and L. M. Rode. 2000 Effects of protozoa on bacterial nitrogen recycling in the rumen. J. Anim. Sci. 78:2431-2445.

Maia, M. R. G., L. C. Chaudhary, L. Figueres, and R. J. Wallace. 2007. Metabolism of polyunsaturated fatty acids and their toxicity to the microflora of the rumen. Antonie Van Leeuwenhoek 91:303-314.

McGuffey, R K, L. F. Richardson, and J. I. D. Wilkinson. 2001. Ionophores for dairy cattle: Current status and future outlook. J. Dairy Sci. 84(E Suppl.):E194-E203.

Nagaraja, T. G., C. J. Newbold, C. J. Van Nevel, and D. I. Demeyer. 1997. Manipulation of rumen fermentation. Pages 523-632 in The Rumen Microbial Ecosystem. P. N. Hobson and C. S. Stewart, ed. Chapman and Hall, London, UK.

Nagaraja, T. G., and E. C. Titgemeyer. 2007. Ruminal acidosis in beef cattle: The current microbiological and nutritional outlook. J. Dairy Sci. 90(E Suppl.):E17-E38.

Oelker, E. R., C. Reveneau, and J. L. Firkins. 2009. Interaction of molasses and monensin in alfalfa hay- or corn silage-based diets on rumen fermentation, total tract digestibility, and milk production by Holstein cows. J. Dairy Sci. 92:270-285.

Oldick, B. S., and J. L. Firkins. 2000. Effects of degree of fat saturation on fiber digestion and microbial protein synthesis when diets are fed twelve times daily. J. Anim. Sci. 78:2412-2420.

Ozutsumi, Y., K. Tajima, A. Takenaka, and H. Itabashi. 2006. Realtime PCR detection of the effects of protozoa on rumen bacteria in cattle. Curr. Microbiol. 52:158-162.

Paillard, D., N. McKain, L. C. Chaudhary, N. D. Walker, F. Pizette, I. Koppova, N. R. McEwan, J. Kopecny, P. E. Vercoe, P. Louis, and R. J. Wallace. 2007. Relation between phylogenetic position, lipid metabolism and butyrate production by different Butyrivibrio-like bacteria from the rumen. Antonie Leeuwenhoek 91:417-422.

Qiu, X., M. L. Eastridge, K. E. Griswold, and J. L. Firkins. 2004. Effects of substrate, passage rate, and $\mathrm{pH}$ in continuous culture 
on flows of conjugated linoleic acid and trans $\mathrm{C}_{18: 1}$. J. Dairy Sci. 87:3473-3479.

Ribeiro, C. V. D. M., S. K. R. Karnati, and M. L. Eastridge. 2005. Biohydrogenation of fatty acids and digestibility of fresh alfalfa or alfalfa hay plus sucrose in continuous culture. J. Dairy Sci. 88:4007-4017.

Russell, J. B., and A. J. Houlihan. 2003. Ionophore resistance of ruminal bacteria and its potential impact on human health. FEMS Microbiol. Rev. 27:65-74.

SAS Institute. 1999. What's New in SAS Software for Version 7 and the Version 8 Developer's Release. Release 7 ed. SAS Inst., Cary, NC.

Shingfield, K. J., C. K. Reynolds, G. Hervás, J. M. Griinari, A. S Grandison, and D. E. Beever. 2006. Examination of the persistency of milk fatty acid composition responses to fish oil and sunflower oil in the diet of dairy cows. J. Dairy Sci. 89:714-732.

Stewart, C. S., H. J. Flint, and M. P. Bryant. 1997. The rumen bacteria. Pages 10-72 in The Rumen Microbial Ecosystem. P. N. Hobson and C. S. Stewart, ed. Blackie Academic and Professional, New York, NY.

Sylvester, J. T., S. K. R. Karnati, B. A. Dehority, M. Morrison, G. L. Smith, N. R. St-Pierre, and J. L. Firkins. 2009. Rumen protozoa decrease generation time and adjust $18 \mathrm{~S}$ ribosomal DNA copies to adapt to decreased transfer interval, starvation, and monensin. J. Dairy Sci. 92:256-269.

Sylvester, J. T., S. K. R. Karnati, Z. Yu, M. Morrison, and J. L. Firkins, 2004. Development of an assay to quantify rumen ciliate protozoal biomass in cows using real-time PCR. J. Nutr. 134:3378-3384.

Sylvester, J. T., S. K. R. Karnati, Z. Yu, C. J. Newbold, and J. L. Firkins. 2005. Evaluation of a real-time PCR assay for measuring the ruminal pool and duodenal flow of protozoal nitrogen. J. Dairy Sci. 88:2083-2095.

Ungerfeld, E. M., S. R. Rust, D. R. Boone, and Y. Liu. 2004. Effects of several inhibitors on pure cultures of ruminal methanogens. J. Appl. Microbiol. 97:520-526.

Ushida, K., B. Lassalas, and J.-P. Jouany. 1985. Determination of assay parameters for RNA analysis in bacterial and duodenal samples by spectrophotometry. Influence of sample treatment and preservation. Reprod. Nutr. Dev. 25:1037-1046.

Van Soest, P. J., J. B. Robertson, and B. A. Lewis. 1991. Methods for dietary fiber, neutral detergent fiber, and nonstarch polysaccharides in relation to animal nutrition. J. Dairy Sci. 74:3583-3597.
Vlaeminck, B., V. Fievez, D. Demeyer, and R. J. Dewhurst. 2006. Effect of forage:concentrate ratio on fatty acid composition of rumen bacteria isolated from ruminal and duodenal digesta. J. Dairy Sci. 89:2668-2678.

Walker, N. D., C. J. Newbold, and R. J. Wallace. 2005. Nitrogen metabolism in the rumen. Pages $71-115$ in Nitrogen and Phosphorus Nutrition of Cattle. E. Pfeffer and A. Hristov, ed. CABI Publishing, Cambridge, MA.

Weimer, P. J., D. M. Stevenson, D. R. Mertens, and E. E. Thomas. 2008. Effect of monensin feeding and withdrawal on populations of individual bacterial species in the rumen of lactating dairy cows fed high-starch diets. Appl. Microbiol. Biotechnol. 80:135-145.

Williams, A. G., and G. S. Coleman. 1992. The Rumen Protozoa. Springer-Verlag, New York, NY.

Williams, A. G., and G. S. Coleman. 1997. The rumen protozoa. Pages 73-139 in The Rumen Microbial Ecosystem. P. N. Hobson and C. S. Stewart, ed. Blackie Academic and Professional, New York, NY.

Wolin, M. J., T. L. Miller, and C. S. Stewart. 1997. Microbe-microbe interactions. Pages 467-491 in The Rumen Microbial Ecosystem. P. N. Hobson and C. S. Stewart, ed. Blackie Academic and Professional, New York, NY.

Wu, Z., O. A. Ohajuruka, and D. L. Palmquist. 1991. Ruminal synthesis, biohydrogenation, and digestibility of fatty acids by dairy cows. J. Dairy Sci. 74:3025-3034.

Yáñez-Ruiz, D. R., N. D. Scollan, R. J. Merry, and C. J. Newbold. 2006. Contribution of rumen protozoa to duodenal flow of nitrogen, conjugated linoleic acid and vaccenic acid in steers fed silages differing in their water-soluble carbohydrate content. $\mathrm{Br}$ J. Nutr. 96:861-869.

Yáñez-Ruiz, D. R., S. Williams, and C. J. Newbold. 2007. The effect of absence of protozoa on rumen biohydrogenation and the fatty acid composition of lamb muscle. Br. J. Nutr. 97:938-948.

Ziemer, C. J., R. Sharp, M. D. Stern, M. A. Cotta, T. R. Whitehead, and D. A. Stahl. 2000. Comparison of microbial populations in model and natural rumens using $16 \mathrm{~S}$ ribosomal RNA-targeted probes. Environ. Microbiol. 2:632-643.

Zinn, R. A., and F. N. Owens. 1986. A rapid procedure for purine measurement and its use for estimating net ruminal protein synthesis. Can. J. Anim. Sci. 66:157-166. 